Additional Perspectives articles for Influenza: The Cutting Edge book collection are available at http://perspectivesinmedicine.cshlp.org/cgi/collection/influenza_the_cutting_edge.

\title{
Experimental Approaches to Identify Host Factors Important for Influenza Virus
}

\author{
Grace A. Schaack and Andrew Mehle \\ Department of Medical Microbiology and Immunology, University of Wisconsin Madison, Madison, \\ Wisconsin 53706, USA \\ Correspondence: amehle@wisc.edu
}

An ever-expanding toolkit of experimental methods provides the means to discover and characterize host factors important for influenza virus. Here, we describe common methods for investigating genetic relationships and physical interactions between virus and host. A comprehensive knowledge of host:virus interactions is key to understanding how influenza virus exploits the host cell and to potentially identify vulnerabilities that may be manipulated to prevent or treat disease.

\section{WHY SHOULD WE STUDY HOST FACTORS IMPORTANT FOR INFLUENZA VIRUS?}

D efining the host:viral interface is central to the study of viral pathogenesis. All viruses rely on host cell machinery for successful completion of their replication cycles, and every contact point between virus and host represents a potential therapeutic target for the treatment of viral infectious disease.

The current mechanistic mainstay for antiviral therapy is inhibition of viral protein function. In the case of influenza virus, adamantanes target the M2 proton channel to inhibit viral uncoating, neuraminidase inhibitors block virion release, and the new viral polymerase inhibitors prevent transcription or replication of viral RNAs, thereby inhibiting viral replication (see Wilson and Lan 2019; Wu and Wilson 2019; Yewdell 2019). Such therapies place significant selective pressure on these highly adaptable RNA viruses, rapidly selecting for drug resis- tance. Drug-resistant variants have arisen for all clinically approved treatments: (1) adamantanes were the first approved anti-influenza compounds but are now ineffective as all viruses currently circulating in humans have acquired resistance mutations (Fiore et al. 2011); (2) oseltamivir-resistant viruses were prevalent in the 2007-2008 influenza season, associated with infection clusters in 2009, and found in emerging H7N9 viruses in China (WHO 2009; Chen et al. 2011; Gao et al. 2013); and (3) resistance to the polymerase-targeted baloxavir arose during the first influenza season in which it was used (Mifsud et al. 2019). There is a clear need to identify new antiviral targets and develop novel antiviral therapies, especially those that are less prone to escaping treatment.

Although the rapid, error-prone replication of viruses selects for drug-resistant mutations in the viral genome, host factors represent attractive therapeutic targets as they are unlikely to change under an antiviral pressure. Using

Editors: Gabriele Neumann and Yoshihiro Kawaoka

Additional Perspectives on Influenza: The Cutting Edge available at www.perspectivesinmedicine.org

Copyright (C) 2020 Cold Spring Harbor Laboratory Press; all rights reserved; doi: 10.1101/cshperspect.a038521

Cite this article as Cold Spring Harb Perspect Med 2020;10:a038521 
host-targeting drugs in the treatment of viral disease has precedence-antiretroviral compounds that target the host coreceptor CCR5 block HIV replication (Brelot and Chakrabarti 2018) - but finding host factors that can be safely targeted without major adverse effects for the patient is a challenge that requires a comprehensive understanding of host:viral interactions.

The study of host:viral interactions also offers broader insights into cell biology, immunology, virology, and viral pathogenesis. Examining the roles of host factors in influenza virus infection often concurrently reveals the functions of these factors in uninfected cells or in innate immune responses. As an impactful historical example, influenza A virus was the model virus used in the discovery of interferon (Lindenmann et al. 1957). Thus, initial discovery of a factor restricting influenza virus infection ultimately helped define a major, broadly acting host antiviral mechanism with wide impacts on the fields of virology and immunology.

The capacity for influenza virus to jump between host species adds another layer of importance to the study of host:influenza virus interactions. Each species that the virus encounters presents a different set of host factors with which the virus can interact, unique restriction and dependency factors that constrain cross-species transmission, and different immune system components with which the virus must cope (Long et al. 2019b). In some instances, the difference between host environments is too great and the virus is unable to successfully replicate. But, in other scenarios, the virus is able to efficiently exploit its new environment. When this transmission occurs into an immunologically naive population, the virus can replicate relatively unfettered, potentially causing high-pathogenicity infections with pandemic potential. Knowledge of host:influenza virus interactions and the degree to which these interactions are conserved across different host species can be used to gauge the strength of species barriers to transmission and pathogenesis in different hosts.

The discovery of host factors impacting influenza virus infection has always paralleled the study of influenza virus itself. Global or systems- level approaches directed at host factor identification are relatively young areas of research that have grown alongside technologic advancements in genetics, RNA biology, and protein biochemistry. As new tools are developed in these and other fields, they are adapted and built upon to create new methods for interrogating host:viral interactions (Fig. 1). In this review, we will focus on approximately the last decade of advances in experimental approaches to identify and characterize host factors that affect influenza viruses. These approaches are not unique to influenza virus research and can be exploited in many different settings to understand host:pathogen interactions.

\section{GENERAL CONSIDERATIONS FOR IDENTIFYING HOST FACTORS IMPORTANT FOR INFLUENZA VIRUS REPLICATION}

A general pipeline for studying host:virus interactions includes identification of candidate host factors, validation of these interactions, and mechanistic studies to understand their effect(s) on viral replication. There are many variables to consider when designing a study under this framework that will ultimately define the scope and determine which experimental approaches are best-suited to accomplish the goals of the study. These factors include the following.

\section{Type of Host:Viral Interaction}

Deciding what type of host:viral interaction to explore is one of the first and most important decisions, as it will impact all of the subsequent experimental approaches and even circumscribe what type of host interactors you will be able to identify. Is this a "genetic" screen or selection? If so, approaches that measure or manipulate host gene expression may be most beneficial, such as expression profiling, RNAi, or CRISPR-Cas approaches. Or, are you searching for "physical" interactors? Protein:protein interactions can be identified using affinity purification-mass spectrometry (AP-MS) and yeast two-hybrid or complementation assays. What if you are more interested in protein:RNA complexes? Crosslinking immunoprecipitation (CLIP)-Seq will 


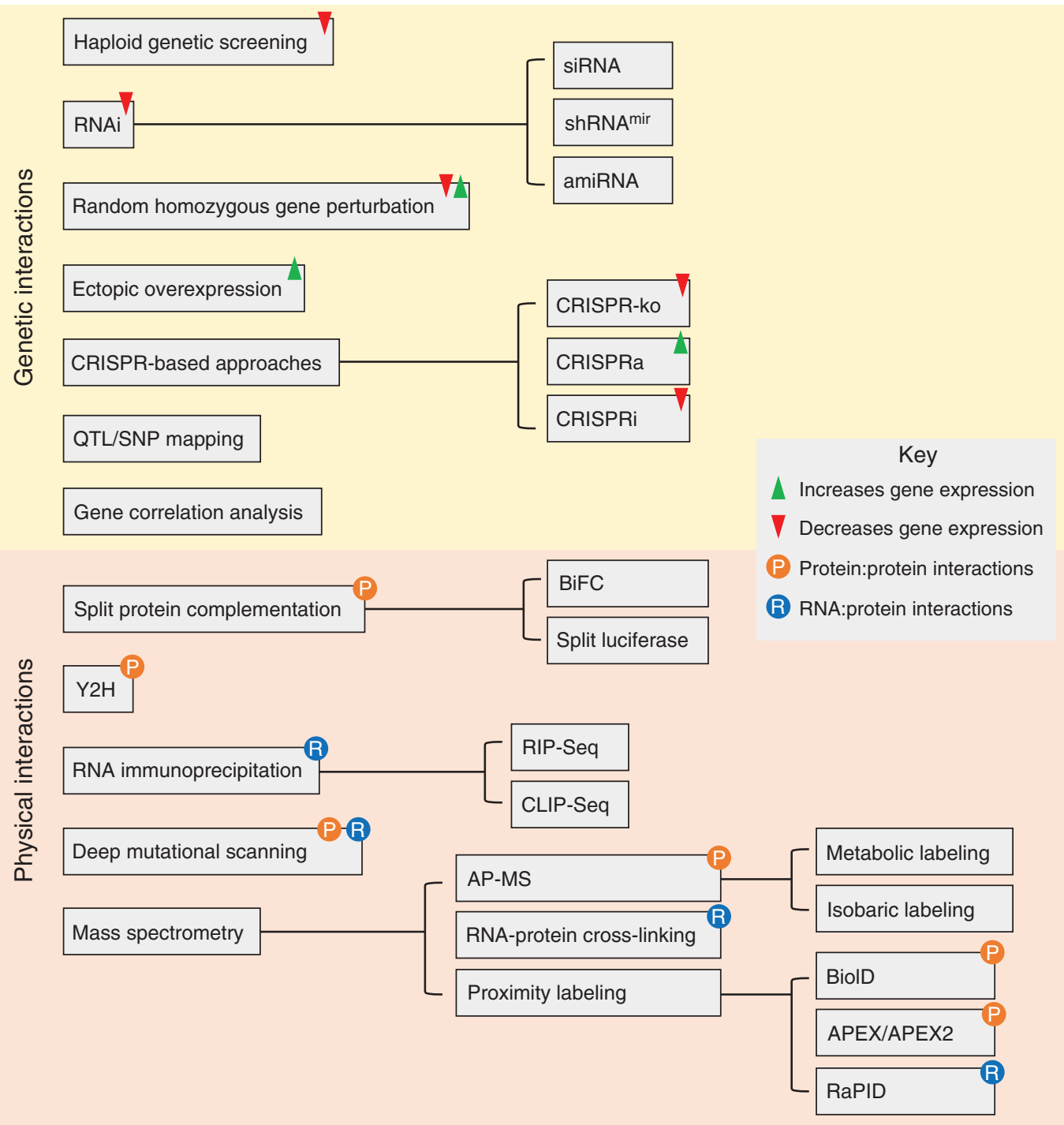

Figure 1. Methods to study host:viral interactions. See text for more detailed discussion of each approach including variations, advantages, and limitations. Rigorous studies frequently use multiple techniques to leverage their synergistic advantages and minimize individual limitations. Genetic interactions are probed by increasing or decreasing target gene expression as indicated. Physical interactions have been labeled as to whether they detect protein:protein or protein:RNA associations. (CRISPR-ko) CRISPR knockout, (CRISPRa) CRISPR activation, (CRISPRi) CRISPR interference, (QTL) quantitative trait loci, (SNP) single-nucleotide polymorphism, (BiFC) bimolecular fluorescence complementation, (Y2H) yeast two-hybrid, (RIP-Seq) RNA immunoprecipitation sequencing, (CLIP-Seq) cross-linking immunoprecipitation sequencing, (AP-MS) affinity purificationmass spectrometry, (BioID) biotin identification, (APEX/APEX2) ascorbate peroxidase, (RaPID) RNA:protein interaction detection. 
identify RNAs bound to a protein of interest, while comprehensive identification of RNA-binding proteins by mass spectrometry (ChIRP-MS) identifies proteins bound to an RNA of interest. Answering these questions early in the planning process is essential for ensuring that the subsequent experiments address the larger biological question that motivated the study in the first place.

\section{Stage(s) of Viral Replication Cycle}

Different assays and screening approaches examine different stages of the influenza viral replication cycle. Some screens measure expression of viral genes (or a virally encoded reporter) in a single-cycle setting. This focusses the screen on host factors that affect early stages of infection, beginning with attachment and continuing to the process of gene expression. Such screens may not reliably detect host factors important for late stages of infection, including genome replication, trafficking, assembly, and budding. A screen designed to uncover host:viral interactions involved in postentry events, on the other hand, might bypass canonical viral entry to ensure that the resulting list of hits will not be dominated by entry factors. Other screens measure replication by assessing cytopathic effect of the infected cells or viral titers produced following infection. This approach captures key host factors required throughout the entire viral life cycle but can be more complicated because of the requisite additional experimental steps. Screens that rely on fitness-based competition will require multiple rounds of replication.

\section{Proviral, Antiviral, or Both?}

The type of experimental approach will dictate what type of host factors can be found. Genetic selection, in which cells containing the desired change survive, can identify both anti- and proviral factors. When used in a gain-of-function setting, selection is a powerful tool to identify antiviral factors that restrict infection or replication and confer survival. Conversely, lossof-function selections are ideally suited for identifying proviral host factors essential for replication. As opposed to selection, in which the readout is binary (e.g., alive or dead), genetic screens offer a continuum of phenotypes that can be scored. The dynamic range can be tuned to focus on pro- or antiviral phenotypes. Most host factors identified by RNAi-based approaches are proviral host factors, although important exceptions exist (see section on RNAi-Based Methods below). Viruses in a fitness-based screen will become enriched or drop out depending on whether their host target is pro- or antiviral, and the assay can be manipulated to bias one outcome over the other. Experiments that rely on physical interactions to identify host factors do not have the same assumptions built in, and the pro- or antiviral effect of host factors often must be determined during subsequent assays.

\section{Is This Thing On?}

Regardless of approach, all experiments should include appropriate controls. This extends beyond obvious positive and negative controls and should incorporate prior results from other host: virus interaction studies. Using what is already known about the influenza viral replication cycle as a guide, certain components of viral and host cell machinery can be anticipated in newly generated data sets, providing confidence in the approach and giving context to novel host:viral interactions. For example, studies focused on host factors controlling influenza virus attachment and entry should almost certainly identify cellular pathways involving sialic acid and its synthesis. Building these assumptions into the approach can also help guide the experimental design to explore new space. Considering attachment and entry again, the use of a pseudotyped influenza virus could avoid the rediscovery of sialic acid and shift the experimental focus to later steps in the entry process.

\section{Influenza Virus Strain(s) of Interest}

Many studies use laboratory-adapted strains of influenza virus, exploiting their ease of use, extensive characterization, and the large number of experimental tools that have already been de- 
veloped in these viruses. But, by their nature as laboratory-adapted variants, these viruses do not always capture all of the features of primary influenza virus isolates. Although primary isolates better reflect viruses circulating in their natural hosts, they can be harder to use in experimental settings and may even undergo laboratory adaptation during a screen. The choice of virus extends further when one considers different types of influenza viruses $(A, B, C, D)$, viruses from other hosts like avian or swine isolates, and seasonal and pandemic clinical isolates. The benefits and limitations of the chosen virus strains should be carefully considered and adjusted to the question at hand. Often, inclusion of different influenza viruses during the validation stage strengthens the claims and broadens the impact of the study.

\section{Relevant Host Model System(s)}

The choice of host in the experimental design is critical in studies of host:viral interactions. Different cell lines, animal models, and clinical samples present different sets of host factors to the infecting virus. Therefore, the results of any investigation of host:viral interactions are inherently constrained by the set of factors at play in the chosen host. When selecting host models, consider the potential impact of species, sex, tissue type, tissue architecture, genetic background, immune system status, and population diversity on the study. If possible, findings in one experimental host should be corroborated in a different host setting to enhance the robustness of the conclusions.

\section{METHODS FOR IDENTIFICATION AND CHARACTERIZATION OF HOST FACTORS IMPORTANT FOR INFLUENZA VIRUS}

Here we discuss the landscape of experimental approaches used to study host:influenza virus interactions, separated into genetic and physical approaches. We focus predominantly on host: viral interactions at the cellular and molecular level with humans as the major host of interest, but these approaches could be expanded to study extracellular interactions and other host
Approaches to Identify Host Factors for Influenza

species as well. This review provides an overview of the experimental approaches used to study host:influenza virus interactions (additionally, see Crowe 2019 and Cusack 2019, who nicely summarize the host factors themselves that regulate influenza virus replication). Identifying host factors, as described below, is often just the first step. A detailed mechanistic understanding of particular host:viral interactions requires specialized assays, such as those in this recent collection (Yamauchi 2018).

Genetic Approaches for Investigating Host: Viral Interactions

\section{RNAi-Based Methods}

RNA interference (RNAi) offers a rapid and scalable approach to disrupt gene expression (Mohr et al. 2014). Small interfering RNAs (siRNAs) are 21-23 nt RNA duplexes introduced into cells, where they program the RNA-induced silencing complex (RISC) to recognize and degrade target mRNAs. Specificity is conferred by base-pairing between the guide strand of the siRNA and the target mRNA, with siRNAs designed to uniquely target individual messages. This enables loss-of-function screening, often performed on a genome-wide scale. Most high-throughput screens array siRNAs in multiwell formats in which each condition uniquely targets one of the $\sim 18,000$ genes in the human genome. Cells are transfected with siRNAs, followed by incubation to ensure efficient silencing, and ultimately inoculation with influenza virus. Infection is quantified to identify cellular factors that are required for infection or those that suppress infection, in which target knockdown prevents or enhances infection, respectively.

The first genome-wide RNAi screen for host factors impacting influenza virus infection was performed in Drosophila cells (Hao et al. 2008). Drosophila is not a native host for influenza virus, but this system allowed genetic analysis of key regulators of infection and gene expression before screening in more relevant models was developed. This initial screen was followed rapidly by multiple genome-wide siRNA screens in mammalian cell lines, uncovering a large num- 
ber of pro- and antiviral host factors (Brass et al. 2009; Shapira et al. 2009; Karlas et al. 2010; König et al. 2010; Ward et al. 2012; Su et al. 2013). These screens are typically well-suited for identification of proviral factors as detection of a decrease in infection relative to wild-type cells is generally more robust, especially when cell viability is used as a screening readout. Nonetheless, perhaps one of the more impactful findings was the identification of the antiviral factor IFITM3, a restriction factor found in a genomewide siRNA screen using influenza virus and shown to block entry of multiple diverse viruses (Brass et al. 2009).

The primary advantages of traditional siRNA screens include the commercial availability of premade genome-wide libraries, the compatibility of screening with high-throughput workflows, and the speed and ease of the transfect-infect approach. However, these advantages come at a cost. Independent siRNA screens for influenza virus host factors show limited overlap, with only $\sim 8 \%$ of the identified genes appearing in more than one screen (Mehle and Doudna 2010; Hao et al. 2013). Some of this variation can be attributed to obvious causes, such as differences in experimental approaches. Other sources of variation are intrinsic to the use of siRNAs and are much harder to address. The limitations of siRNA screens, including serious concerns regarding specificity, have been nicely summarized elsewhere (Goff 2008; Kaelin 2012; Hao et al. 2013). Off-target effects can be ameliorated in part post facto by bioinformatically identifying major off-target transcripts in genome-wide screening data sets (Sigoillot et al. 2012). Additionally, incorporating orthogonal data streams can help bootstrap support for targets, as was performed when results from RNAi screening, yeast two-hybrid analysis, and expression profiling were combined to create a network of interactors during influenza virus infections (Shapira et al. 2009). The use of orthogonal approaches can reinforce results from any of the screening methods described here. Extra care must be taken to incorporate high quality data with a focus on high-confidence targets to avoid compounding the error inherent in the different approaches.
Variations and improvements on the basic siRNA screening theme have emerged. The original genome-wide approach queries each gene one at a time. This approach yields detailed information on individual genes but requires high-throughput assays and cannot be performed in bulk. These issues can be circumvented by the used of short hairpin RNAs (shRNAs) or shRNA ${ }^{\mathrm{mir}}$ s. Both are processed into siRNAs by cellular machinery that normally creates miRNAs. The scaffolds of shRNA ${ }^{\text {mir }}$ s have been further redesigned to produce more potent and specific siRNAs (Chang et al. 2006). shRNAs and shRNA ${ }^{\text {mir }}$ s can be stably expressed in target cells, enabling pooled screening (Bassik et al. 2009). shRNAs were also used in arrayed screening for influenza virus host factors (Tran et al. 2013).

In a clever approach, the shRNA strategy was further coopted to encode and express artificial microRNAs (amiRNAs) from the influenza virus genome (Varble et al. 2010). The influenza virus amiRNA approach condenses both infection and siRNA delivery into a single step. Importantly, it allows the infection to shift from cell culture to animal models. Moreover, the amiRNA has the capacity to alter the fitness of the virus in which it is encoded. Viruses encoding amiRNAs directing knockdown of antiviral genes will gain a fitness advantage and dominate the viral population. Use of amiRNAs enabled an in vivo RNAi screen for regulators of influenza virus replication (Benitez et al. 2015). This competition-style infection in mice identified Ifih1 (the murine ortholog of MDA-5) as an important antiviral effector in the host response to influenza virus infection (Benitez et al. 2015). In theory, drop-screens could also be used to identify viruses encoding amiRNAs that are lost during passaging, presumably because the amiRNA conferred a fitness cost by targeting a critical cellular cofactor. Because the infecting virus in this system brings its own amiRNA to the host cell, target transcripts are only knocked down in infected cells. This opens up opportunities to study selective knockdown of gene expression in infected cells without the need to first generate genetic knockouts. This is useful in the study of multifunctional host 
factors that may be difficult to study in traditional whole-animal genetic knockout models. This is especially true for host factors with differing roles in infected versus uninfected cells.

\section{Knockout-Based Screens or Selections}

Loss-of-function screening underwent a massive advance when technologies were developed to create homozygous knockouts on a genomewide scale. This began with a flurry of screens using gene knockouts in haploid human cells, and the pace of screening accelerated even more with the development of CRISPR-Cas9 systems that rapidly create genome-wide knockouts in almost any cell type.

Early methods for creating gene knockouts in cells relied on random mutagenesis. However, given its stochasticity, this technique could not readily mutate both alleles in diploid cells or the multiple alleles present in polyploid cell lines commonly used for tissue culture. Thus, very few homozygous knockouts could be created, and the approach could not be used on a genome-wide scale. This limitation was overcome by using human cells that are naturally haploid, specifically KBM7 cells and derivatives like HAP-1 cells, dramatically simplifying the creation of knockouts (Carette et al. 2009). Gene knockouts are created by insertional mutagenesis using a gene trap. A sufficient number of cells are transduced to allow for saturating mutagenesis. Mutagenized cells are then selected with a viral challenge or other insult, and surviving cells are isolated. Multiple rounds of selection can be performed to further enrich top candidates. Gene-trap insertion sites are mapped by deep sequencing to identify gene knockouts that presumably confer survival. Statistical analysis identifies gene knockouts that are enriched following selection relative to their abundance in the starting population. The recovery of multiple uniquely integrated gene traps in the same gene reinforces the importance of that locus for viral infection. The power of haploid knockout screens was confirmed when influenza virus challenge selected for cells mutated in genes encoding sialic acid production machinery, preventing virion attachment and infection (Carette et al. 2009). Important host:virus interactions in many different viral systems have since been discovered using haploid knockout screens (Puschnik et al. 2017). Random homozygous gene perturbation (RHGP), wherein insertional mutagenesis results in either overexpression of a gene or disruption of a gene while simultaneously creating antisense RNA that silences the other alleles, has also been used to study influenza virus host factors (Sui et al. 2009).

Haploid screening is very powerful, but it is constrained to the haploid cell line and relies on random integration of the gene trap. These limitations have been overcome using CRISPRCas-based approaches, which have largely supplanted other knockout screening strategies (Doench 2017). In contrast to haploid screens, so-called CRISPR screens or CRISPR-knockout screens use targeted gene knockout and can be performed in almost any cell type. CRISPR-Cas systems are naturally occurring components of bacterial and archaeal adaptive immunity that have been engineered into extremely versatile tools for genetic manipulation in eukaryotes. Early engineered CRISPR-Cas systems derived from Streptococcus pyogenes encompass a single-guide RNA (sgRNA) that is bound by and directs the endonuclease Cas9 to discrete sites in DNA (Jinek et al. 2012). Base-pairing between the sgRNA and target loci conveys a high degree of specificity. Once bound, the nuclease cleaves the genomic DNA invoking repair via the errorprone process of nonhomologous end joining. This repair mechanism frequently introduces insertions, deletions, or mutations resulting in frame-shifting events that create a presumptive null allele. The same sgRNA homes Cas9 to each copy of the target in the genome, and retargets cut sites that are faithfully repaired, enabling creation of homozygous knockouts in diploid or polypoid cells. Many different CRISPR-Cas systems have now been described that recognize either DNA or RNA to target specific sequences or initiate nonspecific nuclease activity; these have all been adapted for use in mammalian cells (Pickar-Oliver and Gersbach 2019). 
Multiplexed pools of sgRNAs have been developed that target every gene in the human genome, often with multiple sgRNAs per gene to ensure knockout (Shalem et al. 2014; Wang et al. 2014) (many of these are available at the plasmid repository addgene [see addgene.org]). These are used to create genome-wide knockout cell pools for loss-of-function screens and have enabled numerous screens for host factors essential for infection in many different viral systems (Puschnik et al. 2017). In a typical CRISPR experiment, a Cas endonuclease and an sgRNA are delivered to cells by lentiviral transduction. Because transduction stably integrates the sgRNA into the host genome, the gene targeted in an individual cell is quickly determined by sequencing the associated sgRNA. Screens proceed in a similar fashion to those using haploid cells: saturating mutagenesis is performed with the genome-wide CRISPR-Cas libraries, pooled cells are infected or otherwise challenged, surviving cells are expanded, and if needed, additional rounds of screening or counter-screening are performed. DNA is isolated from the starting cell population and after each round of selection and subjected to deep sequencing. Ideally, multiple replicates of the screen are performed. Several bioinformatic approaches have been developed to robustly identify sgRNAs that are enriched over successive rounds of selection, notably MAGeCK and STARS (Doench et al. 2016; Wang et al. 2019). The identification of multiple sgRNAs targeting the same gene provides additional support for the specificity of the knockout and importance of the gene during infection. A genome-wide CRISPR-knockout screen for influenza virus host factors again identified components of sialic acid metabolism as essential for viral infection and also identified the transcription factor capicua as a negative regulator of cellintrinsic immunity (Han et al. 2018). Most screens to date have been survival-based screens, but other end points or selection strategies could easily be implemented. Important considerations for CRISPR-based screens in general, and those specific to viral screens, have been recently discussed and should be considered carefully in experimental design and execution (Doench 2017; Puschnik et al. 2017).

\section{Manipulating Endogenous Expression with CRISPR-Cas}

In its natural setting in bacteria, an sgRNA directs Cas9 to a specific DNA sequence for cleavage. This basic system has since been refined to use a catalytically inactive Cas9 (dCas9), which still homes to the specified DNA sequence but has no nuclease function. This is the basis for newer CRISPR activation (CRISPRa) and inhibition (CRISPRi) technologies that exploit the programmable dCas9 to modulate gene expression by recruiting transcriptional activators or repressors to specific loci (Qi et al. 2013; Gilbert et al. 2014; Konermann et al. 2014; Dominguez et al. 2016). CRISPRa and CRISPRi enable both gain- and loss-of-function screens, something not achievable in many prior genome-wide surveys of host factors. A CRISPRa screen was performed to identify restriction factors that protect cells from influenza virus infection, revealing B4GALNT2, an enzyme that modifies sialic acids to prevent their use by influenza virus (Heaton et al. 2017). Other CRISPR systems have been developed that directly target RNA instead of host DNA (e.g., Cas13-based approaches), and these could be exploited to target viral or host messages or viral genomes while querying host factors (Terns 2018).

The efficacy of CRISPR-based gene regulation methods is generally comparable to that of earlier, alternative methods including RNAi and ectopic overexpression and affords a higher degree of specificity over RNAi approaches (Smith et al. 2017; Sanson et al. 2018). A CRISPR-Cas knockout, as opposed to knockdown, often provides very penetrant phenotypes affording a strong signal-to-noise ratio. CRISPR screens or selections can be performed on very large scales to bolster confidence with the depth of coverage, the number of unique mutational events in the same gene recovered during selection, independent biological replicates, and statistically robust analysis of sequencing data to identify enrichment. It is important to consider that knockout screens cannot address the role of genes that are essential for cell viability. If the knockout efficiency is high, sgRNAs targeting essential genes will be depleted from the cell population before 
the screen even commences. Knockouts that alter the replication rate of the cell, even if the target is not essential per se, will skew their abundance in the population independent of the effects of viral challenge. Transient changes in gene expression, such as those conferred by RNAi or inducible CRISPRa/i, could be more suitable when screening host factors that may also play key roles in cell viability. Although CRISPR-Cas systems have much lower systematic off-target effects than RNAi (Smith et al. 2017), targeting fidelity is still a concern. This can be addressed in part with judicious sgRNA design, choice of target position within the locus of interest, redundancy with multiple sgRNAs targeting each gene, and ultimately complementation of the knockout with a copy of the wild-type gene to reverse the phenotype. Several online tools are available to assist in sgRNA design (Doench 2017). Despite best efforts to design efficient sgRNAs, even on-target CRISPR editing frequently suffers from unintended consequences including mRNA misregulation and aberrant protein expression (Tuladhar et al. 2019). With these considerations in mind, CRISPR-based approaches to investigating host:viral interactions offer extensive versatility and room for innovation.

\section{Ectopic Overexpression}

Many modern genetic approaches to studying host:influenza virus interactions rely on lossof-function, but overexpression systems are also useful as both screening and validation tools. Expression screens are classic approaches to identifying cellular factors that confer susceptibility or resistance to infection, especially in early work that identified receptors for many viruses. More recently, an array of cell lines made to each overexpress one of $>380$ interferon stimulated genes (ISGs) was challenged with a panel of viruses to characterize the antior proviral effects of each ISG across various viruses (Schoggins et al. 2011, 2014). These screens confirmed the restricting activities of IFITM2, IFITM3, and MX1 during influenza virus infection and ultimately identified LY6E as an ISG that enhances influenza virus uncoat-
Approaches to Identify Host Factors for Influenza

ing (Mar et al. 2018). Larger, unbiased screens could be performed with genome-scale expression libraries (Yang et al. 2011). However, cDNAs for ISGs that play important roles during infection may be missing from the library as these ISGs are not expressed under normal conditions and therefore may not be represented in the RNAs used for construction of the library.

\section{Gene Correlation Analysis}

Instead of using exogenous systems to manipulate host gene expression, the inherent differences in gene expression between cell lines can be exploited to identify regulators of viral infection (Kondratowicz et al. 2011; Larson et al. 2019). The NCI-60 panel of cell lines encompasses cancer cell lines derived from nine different human tissues with well characterized transcriptomics, proteomics, and metabolomics for each line (Shankavaram et al. 2007; Su et al. 2011). This panel was originally intended as an anticancer pharmaceutical screening platform, but its use has expanded to screens for pro- and antiviral host factors (Shoemaker 2006; Kondratowicz et al. 2011; Larson et al. 2019). Gene correlation analysis identifies candidate host factors by correlating gene expression with susceptibility to infection across the entire NCI-60 panel. A similar approach is used to correlate susceptibility to infection with the host proteome or metabolome. The lack of artificial manipulation of the target cell is an advantage, and the unbiased nature of the screen permits identification of both pro- and antiviral host factors. However, only genes whose expression varies across cell lines can be identified, and the associated phenotypes may be subtle. This approach was recently used to identify EPS8 as a proviral host factor that facilitates virion uncoating during influenza virus infection and to confirm the restricting activity of IFITM3 (Larson et al. 2019).

\section{Expression Profiling}

A conceptually simple method, expression profiling quantifies changes in the host transcriptome in response to infection or another stimulus using microarrays or RNA sequencing. 
Because microarray-based detection is limited to the particular probes on the array and has a narrow dynamic range, RNA-Seq has emerged as a more powerful method. Expression profiling was used to assess host transcriptomic changes in response to influenza virus infection compared with interferon (IFN)- $\beta$ treatment, identifying a set of virus-specific responsive genes for which expression level changes were not attributable to IFN- $\beta$ (Shapira et al. 2009). This approach was also used to look for unique changes in host expression in response to infection with a highly pathogenic avian influenza H5N1 virus (Li et al. 2011). An advantage of expression profiling is the lack of host manipulation, making this approach relatively unbiased and easily applicable to quantifying both increases and decreases in gene expression in a variety of host systems, including animal models. However, this approach only yields information at the transcript level and does not directly inform how any particular host factor affects viral replication. It is therefore often coupled with other screening methods (Shapira et al. 2009; Shoemaker et al. 2012).

\section{Single-Nucleotide Polymorphism (SNP) Analysis}

Identifying genetic susceptibilities to influenza virus infection both illuminates specific host genes impacting influenza viral pathogenesis and provides potentially prognostic information for patients with high-risk mutations, allowing for targeted prophylactic and treatment interventions. A study of patients requiring hospitalization following influenza virus infection correlated a specific SNP in the IFITM3 locus with severe influenza disease (Everitt et al. 2012). It was subsequently shown that this SNP disrupted the promoter and reduced IFITM3 expression, increasing susceptibility to influenza A virus infection (Allen et al. 2017). Similar approaches in experimental animal models address host genetic determinants of influenza pathogenesis in a more controlled setting. Mice from the Collaborative Cross (CC) are highly genetically diverse, making them better models of the wide genetic diversity of human populations than genetically homogeneous inbred mouse strains (Noll et al. 2019). Mx1, a well-known anti-influenza viral host factor in mice, is deleted in common inbred mouse strains. A study of CC mice infected with influenza A virus identified variation in $M x 1$ by quantitative trait loci mapping as a correlate of disease severity, including a novel $M x 1$ allele that was less restrictive to viral replication yet was protective against weight loss in the mice (Ferris et al. 2013).

\section{Investigation of Physical Host:Viral Interactions}

\section{Yeast Two-Hybrid Screens}

First described in 1989, yeast two-hybrid screens have been a workhorse for identifying pairwise protein:protein interactions (Paiano et al. 2019). This approach relies on protein:protein interactions in yeast to reconstitute a transcription factor that drives expression of a selectable marker. Although the assay is performed in yeast, interactions between proteins from almost any species can be studied. In the context of host: pathogen interactions, viral proteins serve as "bait" to screen "prey" libraries composed of host proteins. This approach was used to test pairwise interactions between 10 influenza $A$ virus proteins and $\sim 12,000$ human proteins, ultimately identifying 56 human proteins that interact with viral proteins from both A/Puerto Rico/8/1934 and A/Udorn/1972 IAV strains (Shapira et al. 2009). Focusing on the influenza viral polymerase, another yeast two-hybrid experiment defined the "FluPol interactome," an interaction network of PB1, PB2, PA, and NP with human proteins derived from multiple tissues (Tafforeau et al. 2011). Interactions with viral protein complexes have also been explored. Two viral polymerase subunits were coexpressed in yeast two-hybrid screens to identify cellular factors that interact specifically with the viral protein dimer, providing the first indication that the RED-SMU1 complex of spliceosomal factors interacts with the influenza viral polymerase (Fournier et al. 2014).

A major advantage of this approach is the ease of using yeast as the experimental platform, the existence of highly optimized two-hybrid 
screening systems, and the scalability to almost any number of bait and prey combinations. Yet, although yeast two-hybrid screens can make initial identifications fairly quickly, results require extensive validation. Of primary concern, the assay only measures potential protein:protein interactions completely removed from the normal infection setting. Complementing yeast two-hybrid data with more recent technologies like split-protein complementation or AP-MS in mammalian cells (see below) can add important context and support to the results (Causier 2004; Fournier et al. 2014). Although still an important tool, yeast two-hybrid methods have largely been supplanted by these newer technologies.

\section{Split Luciferase Complementation and Bimolecular Fluorescent Complementation (BiFC)}

Similar to yeast two-hybrid approaches, split protein complementation assays rely on protein:protein interactions to restore activity to a heterologous reporter protein. Structure-guided studies revealed how common reporter proteins like green fluorescent protein (GFP) or luciferase can be split into two polypeptides that are inactive in isolation, but activity is restored when the subunits interact to reconstitute the original protein. These systems have been designed such that reconstitution does not occur spontaneously but rather relies on bridging by other partners (i.e., when the subunits are fused to proteins that interact with each other). Split protein complementation assays are used to probe interactions between discrete protein pairs and to perform larger screens between bait proteins and prey libraries. In luciferase complementation assays, one fragment of luciferase is fused to a protein of interest (e.g., a viral protein) and the complementing fragment is fused to one or more potential interaction partners (e.g., a library of host factors). Physical interactions among the proteins under study drive their corresponding luciferase fragments into proximity, thereby reconstituting a functional luciferase enzyme and restoring bioluminescence (Deng et al. 2011). Recombinant influenza viruses that express luciferase fragments fused to viral proteins of
Approaches to Identify Host Factors for Influenza

interest allow the split protein complementation approach to be used during infection. Experiments using these viruses rediscovered interactions between the viral polymerase and known interactors that direct nuclear import and uncovered a previously unknown physical interaction between the viral polymerase and the cellular mRNA export factor NXF1, a host factor previously identified in a genetic screen (Hao et al. 2008; Munier et al. 2013). Split luciferase complementation was also used to screen interactions between the polymerase subunit PB2 and the ubiquitin-proteasome system, including PB2 from five different influenza strains to identify conserved and robust interactions (Biquand et al. 2017). Given the quantitative nature of the assay, it has been used to measure the strength of host:virus interactions, revealing species-specific differences in binding between the polymerase and the host-range determinant ANP32A (Long et al. 2019a). Bimolecular fluorescent complementation $(\mathrm{BiFC})$ is a similar technique, but fuses proteins of interest to a split fluorescent protein reporter system (Kamiyama et al. 2016). Fluorescence is detected from cells in which BiFC has occurred, implying physical interactions between the two proteins under study. This approach has been used in screening for host-targeting anti-influenza drugs as well as in validation of yeast two-hybrid screening (Tafforeau et al. 2011; Dai et al. 2013).

Both BiFC and luciferase complementation can be implemented in an infection setting in cell culture, an important distinction from yeast two-hybrid approaches. The fluorescence and luminescence readouts are easily quantifiable in a high-throughput fashion using a plate reader or flow cytometry, making data acquisition quick and scalable. BiFC can be used along with live cell imaging to monitor the timing and localization of protein:protein interactions. Reconstitution of the fluorescent protein in BiFC can sometimes be too strong, however, and drive aberrant protein complex formation. The time delay between protein complex formation and fluorescence generation can also be problematic (Kerppola 2013). Split luciferase complementation does not suffer from these limitations, but is not easily adapted to micros- 
copy-based assays. Split luciferase systems have also been used in animal models; bioluminescent imaging of live animals can localize and track protein complexes throughout the course of an infection (Luker and Luker 2011).

\section{Mass Spectrometry Approaches}

The core workflow of AP-MS-based approaches to define host:viral interactions involves AP of a protein or RNA of interest along with any additional copurifying proteins and identification of these interactors by mass spectrometry. The specific extraction and purification conditions determine how well these interactions are preserved and the specificity of the results. Depending on the experimental approach, detected interactions may be direct, such as when a host factor binds to the surface of a viral protein, or indirect, as when protein interactions are bridged via nucleic acids or a daisy chain of interacting proteins. Whereas yeast two-hybrid and split protein complementation approaches are used to individually characterize pairwise interactions, mass spectrometry can be used to explore multiprotein complexes. Additionally, while yeast two-hybrid and split protein complementation methods investigate a set of known potential interaction partners, mass spectrometry approaches can be designed to eliminate this limitation and query the entire proteome in an unbiased manner. Mass spectrometry methods can yield even deeper data sets by profiling not only proteins, but their posttranslational modifications as well. Mass spectrometry is therefore a powerful tool for in vestigating a variety of host:viral interaction types.

For analysis of protein:protein interactions, AP-MS is the basic method on which its many variations are built. After infection or overexpression of the viral protein(s) of interest, host cells are lysed, and the desired protein complexes are isolated by immunoprecipitation or other affinity chromatography techniques. The complexes are washed extensively and processed for mass spectrometry. Proteins detected in the experimental conditions are then compared with background controls. AP-MS is exquisitely sensitive. Although beneficial for detecting rare events, this level of sensitivity entails high false-positive rates. As such, multiple controls and new approaches have been developed to increase the specificity of detection. Tandem AP (TAP) tags are incorporated into target proteins and used for multistep orthogonal purification steps to reduce background contamination (Bauer and Kuster 2003). To stabilize complexes and potentially increase specificity, ultraviolet (UV) or chemical cross-linking can be performed before cell lysis to help preserve biologically relevant interactions during very stringent purification steps (Bauer and Kuster 2003; Lum and Cristea 2016). Metabolic labeling by SILAC or I-DIRT incorporates heavy isotopes in proteins, thereby differentially labeling samples to make them distinguishable during multiplexed mass spectrometry, permitting accurate and quantitative comparisons across experimental conditions and controls (Ong et al. 2002; Tackett et al. 2005). Isobaric tagging via iTRAQ, ICAT, or tandem mass tagging achieves the same goal by covalently attaching isobaric labels to peptides after sample preparation (Rauniyar and Yates 2014). Samples are then pooled for comparative analysis on the same mass spectrometry run, and results are deconvoluted based on the isobaric labels; current approaches allow simultaneous comparison of up to 20 unique samples. AP-MS approaches have been used to develop a comprehensive protein:protein interaction network for all influenza virus proteins (Watanabe et al. 2014; Heaton et al. 2016) and for specific complexes like the viral polymerase or ribonucleoprotein complex (Bradel-Tretheway et al. 2011; York et al. 2014). They have also been used to characterize posttranslational modification of viral and host proteins in response to infection (Hutchinson et al. 2012; Domingues et al. 2015; Mondal et al. 2017).

Proximity-dependent labeling techniques identify protein:protein interactions by using enzymes that covalently tag neighboring proteins with biotin (Chen and Perrimon 2017). This approach combines measurement of native protein:protein interactions with the high affinity and stringency afforded by biotin:avidin purifications. Biotin identification (BioID) and APEX/APEX2 are the dominant proximity- 
dependent labeling strategies. In BioID, the protein of interest is fused to the promiscuous biotin ligase BirA* from Escherichia coli. APEX and APEX2 use a plant ascorbate peroxidase. BirA* labels neighboring proteins within a $10-15 \mathrm{~nm}$ radius, and APEX is thought to be similar (Kim et al. 2014; Chen and Perrimon 2017). BioID is a gentle process that uses endogenous biotin, but the labeling kinetics of BirA* are slow. New variants of BirA* and other biotin ligases have been developed to increase the speed of target modification and subsequent strength of signal (Branon et al. 2018; Ramanathan et al. 2018). APEX2 exploits the much faster labeling by the engineered ascorbate peroxidase but requires harsh reaction conditions. The choice between BioID and APEX2 depends on the desired experimental outcome. Both approaches afford highly specific detection of adjacent proteins and are amenable to high-throughput analysis. Proximity labeling can be integrated into isobaric tagging protocols for highly quantitative readouts. BioID has been used successfully to identify interactions between the viral protein PA-X and cellular proteins involved in mRNA processing, an impressive feat given how poorly PA-X is expressed (Gaucherand et al. 2019).

Although much of the interaction landscape has focused on protein:protein interfaces, a vast number of new technologies have made it easier to quantify protein:RNA interactions on a genome-wide scale (Ramanathan et al. 2019). These approaches query such interactions from both directions: known RNAs are used to capture unknown protein interactors or known proteins are used to capture unknown RNAs. These techniques have begun to reveal just how broadly viral proteins interact with cellular RNAs and how cellular proteins bind viral RNAs. This is an important set of interactions, especially considering that viral RNAs are frequent activators of innate immune responses.

RNA-centered approaches use oligonucleotides to specifically purify RNAs of interest and downstream techniques to identify copurifying proteins. Cross-linking-based methods use either UV (RAP, PAIR, MS2-BioTRAP, TRIP) or formaldehyde cross-linking (CHART, ChIRP, HyPR-MS) to form covalent complexes between
Approaches to Identify Host Factors for Influenza

RNA and proteins (Ramanathan et al. 2019). The RNA of interest is selectively hybridized to biotinylated oligonucleotide probes, captured with avidin resin, washed extensively, and proteins are subsequently analyzed by mass spectrometry or other more targeted analyses. The extremely stable nature of the captured complexes allows very stringent purification and highconfidence identification of specific interactors. While the use of these techniques has not yet been published for proteome-wide studies of influenza virus, they have been used in other viral infections, including identifying cellular proteins that interact with RNA genomes during flavivirus and HIV infections (Knoener et al. 2017; Ooi et al. 2019).

RNA:protein complexes are also identified without the need for cross-linking. The RNA: protein interaction detection (RaPID) method is a proximity labeling methods analogous to BioID described above. RaPID uses an RNA aptamer encoded in the RNA of interest to recruit the promiscuous biotin ligase BirA* (Ramanathan et al. 2018). The ligase nonspecifically biotinylates other proteins bound to the same RNA within a $\sim 10 \mathrm{~nm}$ radius (Kim et al. 2014). The strong and highly specific interaction between biotin and avidin permits very stringent purification of the modified proteins. This approach has been used to identify cellular cofactors that interact with the Zika virus genome (Ramanathan et al. 2018). RNA aptamers have already been encoded into replication-competent influenza virus genomes, suggesting that, as the name implies, RaPID could be quickly applied to study proteins interacting with influenza virus RNAs (York et al. 2013). Further, the orientation in which the aptamer is encoded allows selective isolation of positive- or negative-sense RNAs and their associated proteins.

\section{Sequencing Approaches to Detect RNA: Protein Interactions}

RNA immunoprecipitation-sequencing (RIPSeq) and its derivative cross-linking immunoprecipitation sequencing (CLIP-Seq) are well-suited for identifying RNAs that interact with a protein of interest. In both methods, the 
desired protein is purified, and copurifying RNAs are isolated and sequenced to determine their identity and abundance. A CLIP-Seq experiment includes a cross-linking step before cell lysis to preserve biologically relevant interactions, increase specificity, and prevent isolation of artifactual protein:RNA complexes that spuriously form postlysis (Riley et al. 2012). Crosslinking is typically accomplished with UV irradiation, but chemical cross-linking methods are also available. There is a veritable alphabet soup of different CLIP protocol options (HITS-CLIP, PAR-CLIP, fCLIP, iCLIP, irCLIP, eCLIP, etc.), but they all generally rely on cross-linking an RNA-binding protein to its bound RNA, purifying the RNA:protein complex through multiple steps, trimming RNA, removing protein, reverse transcribing the RNA, and sequencing the resultant cDNA (Ramanathan et al. 2019). If noncovalent or indirect interactions are of interest, however, then RIP-Seq is a better approach. Compared with CLIP-Seq, RIP-Seq offers a dramatically simplified protocol but can be confounded by high levels of background RNA binding and sometimes questionable biological relevance. Both RIP-Seq and CLIP-Seq can be modified from their global scale to query interactions with specific RNAs. RIP-Seq was used to reveal that the cytoplasmic sensor RIG-I binds short viral RNAs derived from influenza genomes or subgenomic defective interfering RNAs (Baum et al. 2010). RIP followed by primer extension also revealed interactions between genomic RNAs and RIG-I as well as interaction between genomes and NS1 that may prevent RIG-I recognition (Rehwinkel et al. 2010). CLIP-seq experiments focusing on influenza viral proteins identified host RNAs bound by NS1 and mapped contact points between NP and the viral genome (Lee et al. 2017; Williams et al. 2018; Zhang et al. 2018). Taking a more hostcentric approach, interactions between host m6A-binding proteins and influenza viral RNA have also been mapped (Courtney et al. 2017).

\section{Deep Mutational Scanning}

Deep mutational scanning (DMS) is a powerful method for detailed characterization of the functional constraints of a protein and the interface between known host and viral interactors. DMS creates a comprehensive and unbiased pool of mutants sampling all possible amino acid substitutions at every amino acid position (Fowler and Fields 2014). The mutant pool is expressed, and the resultant proteins are placed under selection to correlate phenotype with the diversified genotype. DMS was used to explore the species-specific functional constraints for PB2, probing potential host-specific interactions (Soh et al. 2019), DMS also probed known host:virus interfaces of NP by identifying key mutations that alter sensitivity to restriction by MxA. Viruses harboring NP mutations that ablated MxA sensitivity were able to replicate with greater success in MxA-expressing host cells; these mutations were mapped back onto the NP structure to define regions of NP in which MxA-escape mutants are likely to emerge (Ashenberg et al. 2017).

\section{CONCLUDING REMARKS}

Technical advances have enabled massive gains in our knowledge of the host:virus interface. Many studies now use multiple approaches on a genome-wide scale, producing comprehensive interaction networks that build on the strengths of the independent approaches while compensating for their inherent limitations. These systems-level data sets can be integrated into meta-analyses to provide an even deeper understanding and identify cellular hubs impacting many steps during infection (Shoemaker et al. 2012; Matsuoka et al. 2013; Tripathi et al. 2015). Keeping this overall map of influenza virus:host interactions in mind, gaps in knowledge can be identified and novel findings can be interpreted in the context of the larger host:viral interaction network.

As our repertoire of experimental approaches for identification and characterization of host factors important for influenza virus expands, we gain opportunities to explore new questions and revisit old ideas. Newly developed approaches are being used to study diverse topics in virus: host interactions including single-cell virology, next-generation screens, host noncoding RNAs 
in the antiviral immune response, and RNA: RNA interactions. Single-cell studies have already shown that seemingly homogeneous populations of cells and viruses display significant heterogeneity at the single-cell infection level, leading to questions about what makes a single infection of one cell more or less immunogenic than infection of another and how these differences contribute to the immune response as a whole (Russell et al. 2018, 2019). Similar studies have reversed the focus onto the virus, exploring the exact nature of the infectious unit and the processes of co-infection and complementation (Jacobs et al. 2019). Current CRISPR screens use gene-delivery viruses to reconstitute Cas9/ sgRNA complexes for screening. But, there is no reason the virus under study cannot be used itself to program and drive a fitness-based CRISPR screen, building on parallel ideas used to study HIV (OhAinle et al. 2018). Emerging knowledge of the role of host noncoding RNAs in innate immune responses also opens up new questions about how viruses interface with these RNA species (Winterling et al. 2014; Zhang and Cao 2016). Many tools are available to study protein:protein and protein:RNA interactions, but it is becoming clear that RNA:RNA interactions are also important. RNA:RNA interactions between virus and host, although not unusual in virology, are a relatively understudied category of interactions during influenza virus infection (Damas et al. 2019). Tools are already available to study RNA:RNA interactions, and these have provided our first glimpse into how RNA:RNA interactions define influenza virus genome organization (Gong et al. 2018; Dadonaite et al. 2019). Extension of these techniques into host: virus interaction studies opens up entirely new areas of investigation. Thus, creative applications of new techniques to virological questions, paired with thoughtful experimental design and analysis, will continue to yield important insights into the delicate dance occurring between virus and host during infection.

\section{ACKNOWLEDGMENTS}

Work in the Mehle laboratory studying influenza virus host factors is supported by the National
Approaches to Identify Host Factors for Influenza

Institute of Allergy and Infectious Disease (R01AI125271 and R21AI125897). G.A.S. is supported by a Rath Foundation Wisconsin Distinguished Graduate Fellowship. A.M. is a Burroughs Wellcome Fund Investigator in the Pathogenesis of Infectious Disease.

This article has been made freely available online courtesy of TAUNS Laboratories.

\section{REFERENCES}

${ }^{*}$ Reference is also in this collection.

Allen EK, Randolph AG, Bhangale T, Dogra P, Ohlson M, Oshansky CM, Zamora AE, Shannon JP, Finkelstein D, Dressen A, et al. 2017. SNP-mediated disruption of CTCF binding at the IFITM3 promoter is associated with risk of severe influenza in humans. Nat Med 23: 975-983. doi:10 $.1038 / \mathrm{nm} .4370$

Ashenberg O, Padmakumar J, Doud MB, Bloom JD. 2017. Deep mutational scanning identifies sites in influenza nucleoprotein that affect viral inhibition by MxA. PLoS Pathog 13: e1006288. doi:10.1371/journal.ppat.1006288

Bassik MC, Lebbink RJ, Churchman LS, Ingolia NT, Patena W, LeProust EM, Schuldiner M, Weissman JS, McManus MT. 2009. Rapid creation and quantitative monitoring of high coverage shRNA libraries. Nat Methods 6: 443-445. doi: $10.1038 /$ nmeth. 1330

Bauer A, Kuster B. 2003. Affinity purification-mass spectrometry. Eur J Biochem 270: 570-578. doi:10.1046/j 1432-1033.2003.03428.x

Baum A, Sachidanandam R, García-Sastre A. 2010. Preference of RIG-I for short viral RNA molecules in infected cells revealed by next-generation sequencing. Proc Natl Acad Sci 107: 16303-16308. doi:10.1073/pnas .1005077107

Benitez AA, Panis M, Xue J, Varble A, Shim JV, Frick AL, López CB, Sachs D, tenOever BR. 2015. In vivo RNAi screening identifies MDA5 as a significant contributor to the cellular defense against influenza A virus. Cell Rep 11: 1714-1726. doi:10.1016/j.celrep.2015.05.032

Biquand E, Poirson J, Karim M, Declercq M, Malausse N, Cassonnet P, Barbezange C, Straub ML, Jones L, Munier S, et al. 2017. Comparative profiling of ubiquitin proteasome system interplay with influenza A virus PB2 polymerase protein recapitulating virus evolution in humans. mSphere 2: e00330-17. doi:10.1128/mSphere .00330-17

Bradel-Tretheway BG, Mattiacio JL, Krasnoselsky A, Stevenson C, Purdy D, Dewhurst S, Katze MG. 2011. Comprehensive proteomic analysis of influenza virus polymerase complex reveals a novel association with mitochondrial proteins and RNA polymerase accessory factors. J Virol 85: 8569-8581. doi:10.1128/JVI.00496-11

Branon TC, Bosch JA, Sanchez AD, Udeshi ND, Svinkina T, Carr SA, Feldman JL, Perrimon N, Ting AY. 2018. Efficient proximity labeling in living cells and organisms with TurboID. Nat Biotechnol 36: 880-887. doi:10.1038/nbt .4201 
Brass AL, Huang IC, Benita Y, John SP, Krishnan MN, Feeley EM, Ryan BJ, Weyer JL, van der Weyden L, Fikrig E, et al. 2009. The IFITM proteins mediate cellular resistance to influenza A H1N1 virus, West Nile virus, and dengue virus. Cell 139: 1243-1254. doi:10.1016/j.cell.2009.12.017

Brelot A, Chakrabarti LA. 2018. CCR5 revisited: how mechanisms of HIV entry govern AIDS pathogenesis. $J \mathrm{Mol}$ Biol 430: 2557-2589. doi:10.1016/j.jmb.2018.06.027

Carette JE, Guimaraes CP, Varadarajan M, Park AS, Wuethrich I, Godarova A, Kotecki M, Cochran BH, Spooner E, Ploegh HL, et al. 2009. Haploid genetic screens in human cells identify host factors used by pathogens. Science 326: 1231-1235. doi:10.1126/science.1178955

Causier B. 2004. Studying the interactome with the yeast two-hybrid system and mass spectrometry. Mass Spectrom Rev 23: 350-367. doi:10.1002/mas.10080

Chang K, Elledge SJ, Hannon GJ. 2006. Lessons from nature: microRNA-based shRNA libraries. Nat Methods 3: 707714. doi:10.1038/nmeth923

Chen CL, Perrimon N. 2017. Proximity-dependent labeling methods for proteomic profiling in living cells. Wiley Interdiscip Rev Dev Biol 6: e272. doi: 10.1002/wdev.272

Chen LF, Dailey NJM, Rao AK, Fleischauer AT, Greenwald I, Deyde VM, Moore ZS, Anderson DJ, Duffy J, Gubareva LV, et al. 2011. Cluster of oseltamivir-resistant 2009 pandemic influenza A (H1N1) virus infections on a hospital ward among immunocompromised patients-North Carolina, 2009. J Infect Dis 203: 838-846. doi:10.1093/in fdis/jiq124

Courtney DG, Kennedy EM, Dumm RE, Bogerd HP, Tsai K, Heaton NS, Cullen BR. 2017. Epitranscriptomic enhancement of influenza A virus gene expression and replication. Cell Host Microbe 22: 377-386.e5. doi:10.1016/j.chom .2017.08.004

* Crowe J. 2019. Characterization of influenza virus-specific antibodies. Cold Spring Harb Perspect Med doi:10.1101/ cshperspect.a038364

* Cusack S. 2019. Influenza polymerase structure. Cold Spring Harb Perspect Med doi: 10.1101/cshperspect.a038372

Dadonaite B, Gilbertson B, Knight ML, Trifkovic S, Rockman S, Laederach A, Brown LE, Fodor E, Bauer DLV 2019. The structure of the influenza A virus genome. Nat Microbiol 4: 1781-1789. doi: 10.1038/s41564-0190513-7

Dai JP, Zhao XF, Zeng J, Wan QY, Yang JC, Li WZ, Chen XX, Wang GF, Li KS. 2013. Drug screening for autophagy inhibitors based on the dissociation of Beclin1-Bcl2 complex using BiFC technique and mechanism of eugenol on anti-influenza A virus activity. PLoS ONE 8: e61026. doi:10.1371/journal.pone.0061026

Damas ND, Fossat N, Scheel TKH, Damas ND, Fossat N, Scheel TKH. 2019. Functional interplay between RNA viruses and non-coding RNA in mammals. Noncoding RNA 5: 7.

Deng Q, Wang D, Xiang X, Gao X, Hardwidge PR, Kaushik RS, Wolff T, Chakravarty S, Li F. 2011. Application of a split luciferase complementation assay for the detection of viral protein-protein interactions. J Virol Methods 176: 108-111. doi:10.1016/j.jviromet.2011.04.028

Doench JG. 2017. Am I ready for CRISPR? A user's guide to genetic screens. Nat Rev Genet 19: 67-80. doi:10.1038/nrg .2017 .97
Doench JG, Fusi N, Sullender M, Hegde M, Vaimberg EW, Donovan KF, Smith I, Tothova Z, Wilen C, Orchard $\mathrm{R}$, et al. 2016. Optimized sgRNA design to maximize activity and minimize off-target effects of CRISPRCas9. Nat Biotechnol 34: 184-191. doi:10.1038/nbt.3437

Domingues P, Golebiowski F, Tatham MH, Lopes AM, Taggart A, Hay RT, Hale BG. 2015. Global reprogramming of host SUMOylation during influenza virus infection. Cell Rep 13: 1467-1480. doi:10.1016/j.celrep.2015.10.001

Dominguez AA, Lim WA, Qi LS. 2016. Beyond editing: repurposing CRISPR-Cas9 for precision genome regulation and interrogation. Nat Rev Mol Cell Biol 17: 5-15. doi:10.1038/nrm.2015.2

Everitt AR, Clare S, Pertel T, John SP, Wash RS, Smith SE, Chin CR, Feeley EM, Sims JS, Adams DJ, et al. 2012. IFITM3 restricts the morbidity and mortality associated with influenza. Nature 484: 519-523. doi:10.1038/na ture10921

Ferris MT, Aylor DL, Bottomly D, Whitmore AC, Aicher LD, Bell TA, Bradel-Tretheway B, Bryan JT, Buus RJ, Gralinski LE, et al. 2013. Modeling host genetic regulation of influenza pathogenesis in the collaborative cross. PLoS Pathog 9: e1003196. doi:10.1371/journal.ppat.1003196

Fiore AE, Fry A, Shay D, Gubareva L, Bresee JS, Uyeki TM. 2011. Antiviral agents for the treatment and chemoprophylaxis of influenza-recommendations of the Advisory Committee on Immunization Practices (ACIP). MMWR Recomm Reports 60: 1-24.

Fournier G, Chiang C, Munier S, Tomoiu A, Demeret C, Vidalain PO, Jacob Y, Naffakh N. 2014. Recruitment of RED-SMU1 complex by influenza A virus RNA polymerase to control viral mRNA splicing. PLoS Pathog 10: e1004164. doi:10.1371/journal.ppat.1004164

Fowler DM, Fields S. 2014. Deep mutational scanning: a new style of protein science. Nat Methods 11: 801-807. doi:10 $.1038 /$ nmeth.3027

Gao R, Cao B, Hu Y, Feng Z, Wang D, Hu W, Chen J, Jie Z, Qiu H, Xu K, et al. 2013. Human infection with a novel avian-origin influenza A (H7N9) virus. N Engl J Med 368: 1888-1897. doi:10.1056/NEJMoa1304459

Gaucherand L, Porter BK, Levene RE, Price EL, Schmaling SK, Rycroft CH, Kevorkian Y, McCormick C, Khaperskyy DA, Gaglia MM. 2019. The influenza A virus endoribonuclease PA-X usurps host mRNA processing machinery to limit host gene expression. Cell Rep 27: 776-792.e7. doi:10.1016/j.celrep.2019.03.063

Gilbert LA, Horlbeck MA, Adamson B, Villalta JE, Chen Y, Whitehead EH, Guimaraes C, Panning B, Ploegh HL, Bassik MC, et al. 2014. Genome-scale CRISPR-mediated control of gene repression and activation. Cell 159: 647661. doi:10.1016/j.cell.2014.09.029

Goff SP. 2008. Knockdown screens to knockout HIV-1. Cell 135: 417-420. doi:10.1016/j.cell.2008.10.007

Gong J, Ju Y, Shao D, Zhang QC. 2018. Advances and challenges towards the study of RNA-RNA interactions in a transcriptome-wide scale. Quant Biol 6: 239-252. doi:10 .1007/s40484-018-0146-5

Han J, Perez JT, Chen C, Li Y, Benitez A, Kandasamy M, Lee Y, Andrade J, tenOever B, Manicassamy B. 2018. Genome-wide CRISPR/Cas9 screen identifies novel host factors essential for influenza virus replication. Cell Rep 23: 596-607. doi:10.1016/j.celrep.2018.03.045 
Hao L, Sakurai A, Watanabe T, Sorensen E, Nidom CA, Newton MA, Ahlquist P, Kawaoka Y. 2008. Drosophila RNAi screen identifies host genes important for influenza virus replication. Nature 454: 890-893. doi:10.1038/na ture 07151

Hao L, He Q, Wang Z, Craven M, Newton MA, Ahlquist P. 2013. Limited agreement of independent RNAi screens for virus-required host genes owes more to false-negative than false-positive factors. PLoS Comput Biol 9: e1003235. doi:10.1371/journal.pcbi.1003235

Heaton NS, Moshkina N, Fenouil R, Gardner TJ, Aguirre S Shah PS, Zhao N, Manganaro L, Hultquist JF, Noel J, et al. 2016. Targeting viral proteostasis limits influenza virus, HIV, and dengue virus infection. Immunity 44: 46-58. doi:10.1016/j.immuni.2015.12.017

Heaton BE, Kennedy EM, Dumm RE, Harding AT, Sacco MT, Sachs D, Heaton NS. 2017. A CRISPR activation screen identifies a pan-avian influenza virus inhibitory host factor. Cell Rep 20: 1503-1512. doi:10.1016/j.celrep 2017.07.060

Hutchinson EC, Denham EM, Thomas B, Trudgian DC, Hester SS, Ridlova G, York A, Turrell L, Fodor E. 2012. Mapping the phosphoproteome of influenza A and B viruses by mass spectrometry. PLoS Pathog 8: e1002993. doi:10.1371/journal.ppat.1002993

Jacobs NT, Onuoha NO, Antia A, Steel J, Antia R, Lowen AC 2019. Incomplete influenza A virus genomes occur frequently but are readily complemented during localized viral spread. Nat Commun 10: 3526. doi:10.1038/ s41467-019-11428-x

Jinek M, Chylinski K, Fonfara I, Hauer M, Doudna JA, Charpentier E. 2012. A programmable dual-RNA-guided DNA endonuclease in adaptive bacterial immunity. Science 337: 816-821. doi:10.1126/science. 1225829

Kaelin WG Jr. 2012. Molecular biology. Use and abuse of RNAi to study mammalian gene function. Science 337: 421-422. doi:10.1126/science.1225787

Kamiyama D, Sekine S, Barsi-Rhyne B, Hu J, Chen B, Gilbert LA, Ishikawa H, Leonetti MD, Marshall WF, Weissman JS, et al. 2016. Versatile protein tagging in cells with split fluorescent protein. Nat Commun 7: 11046. doi:10.1038/ ncomms 11046

Karlas A, Machuy N, Shin Y, Pleissner K-PP, Artarini A, Heuer D, Becker D, Khalil H, Ogilvie LA, Hess S, et al 2010. Genome-wide RNAi screen identifies human host factors crucial for influenza virus replication. Nature 463: 818-822. doi:10.1038/nature08760

Kerppola TK. 2013. Bimolecular fluorescence complementation (BiFC) analysis of protein interactions in live cells. Cold Spring Harb Protoc 2013: 727-731. doi:10.1101/pdb .prot076497.

Kim DI, Birendra KC, Zhu W, Motamedchaboki K, Doye V, Roux KJ. 2014. Probing nuclear pore complex architecture with proximity-dependent biotinylation. Proc Natl Acad Sci 111: E2453-E2461.

Knoener RA, Becker JT, Scalf M, Sherer NM, Smith LM. 2017. Elucidating the in vivo interactome of HIV-1 RNA by hybridization capture and mass spectrometry. Sci Rep 7: 16965. doi:10.1038/s41598-017-16793-5

Kondratowicz AS, Lennemann NJ, Sinn PL, Davey RA, Hunt CL, Moller-Tank S, Meyerholz DK, Rennert P, Mullin RF, Brindley M, et al. 2011. T-cell immunoglobulin and mucin domain 1 (TIM-1) is a receptor for Zaire Ebolavirus and Lake Victoria Marburgvirus. Proc Natl Acad Sci 108: 8426-8431. doi:10.1073/pnas.1019030108

Konermann S, Brigham MD, Trevino AE, Joung J, Abudayyeh OO, Barcena C, Hsu PD, Habib N, Gootenberg JS, Nishimasu H, et al. 2014. Genome-scale transcriptional activation by an engineered CRISPR-Cas 9 complex. Nature 517: 583-588. doi:10.1038/nature14136

König R, Stertz S, Zhou Y, Inoue A, Hoffmann H-HH, Bhattacharyya S, Alamares JGG, Tscherne DMM, Ortigoza MBB, Liang Y, et al. 2010. Human host factors required for influenza virus replication. Nature 463: 813-817. doi:10.1038/nature08699

Larson GP, Tran V, Yú S, Caì Y, Higgins CA, Smith DM, Baker SF, Radoshitzky SR, Kuhn JH, Mehle A. 2019. EPS8 facilitates uncoating of influenza A virus. Cell Rep 29: 2175-2183. doi: 10.1101/592485

Lee N, Le Sage V, Nanni AV, Snyder DJ, Cooper VS, Lakdawala SS. 2017. Genome-wide analysis of influenza viral RNA and nucleoprotein association. Nucleic Acids Res 45: 8968-8977. doi:10.1093/nar/gkx584

Li C, Bankhead A, Eisfeld AJ, Hatta Y, Jeng S, Chang JH, Aicher LD, Proll S, Ellis AL, Law GL, et al. 2011. Host regulatory network response to infection with highly pathogenic $\mathrm{H} 5 \mathrm{~N} 1$ avian influenza virus. J Virol 85: 10955-10967. doi:10.1128/JVI.05792-11

Lindenmann J, Burke DC, Isaacs A. 1957. Studies on the production, mode of action and properties of interferon. Br J Exp Pathol 38: 551-562.

Long JS, Idoko-Akoh A, Mistry B, Goldhill DH, Staller E, Schreyer J, Ross C, Goodbourn S, Shelton H, Skinner MA, et al. 2019a. Species specific differences in use of ANP32 proteins by influenza A virus. eLife 8: e45066.

Long JS, Mistry B, Haslam SM, Barclay WS. 2019b. Host and viral determinants of influenza A virus species specificity. Nat Rev Microbiol 17: 67-81. doi:10.1038/s41579-0180115-Z

Luker GD, Luker KE. 2011. Luciferase protein complementation assays for bioluminescence imaging of cells and mice. In Methods in molecular biology, Vol. 680, pp. 2943. Springer, Clifton, NJ

Lum KK, Cristea IM. 2016. Proteomic approaches to uncovering virus-host protein interactions during the progression of viral infection. Expert Rev Proteomics 13: 325-340. doi:10.1586/14789450.2016.1147353

Mar KB, Rinkenberger NR, Boys IN, Eitson JL, McDougal MB, Richardson RB, Schoggins JW. 2018. LY6E mediates an evolutionarily conserved enhancement of virus infection by targeting a late entry step. Nat Commun 9: 3603 . doi:10.1038/s41467-018-06000-y

Matsuoka Y, Matsumae H, Katoh M, Eisfeld A, Neumann G, Hase T, Ghosh S, Shoemaker J, Lopes T, Watanabe T, et al. 2013. A comprehensive map of the influenza A virus replication cycle. BMC Syst Biol 7: 97. doi:10.1186/17520509-7-97

Mehle A, Doudna JA. 2010. A host of factors regulating influenza virus replication. Viruses 2: 566-573. doi:10 $.3390 / \mathrm{v} 2020566$

Mifsud EJ, Hayden FG, Hurt AC. 2019. Antivirals targeting the polymerase complex of influenza viruses. Antiviral Res 169: 104545. doi:10.1016/j.antiviral.2019.104545 
G.A. Schaack and A. Mehle

Mohr SE, Smith JA, Shamu CE, Neumüller RA, Perrimon N 2014. RNAi screening comes of age: improved techniques and complementary approaches. Nat Rev Mol Cell Biol 15: 591-600. doi:10.1038/nrm3860

Mondal A, Dawson AR, Potts GK, Freiberger EC, Baker SF, Moser LA, Bernard KA, Coon JJ, Mehle A. 2017. Influenza virus recruits host protein kinase $\mathrm{C}$ to control assembly and activity of its replication machinery. eLife $\mathbf{6}$ e26910. doi:10.7554/eLife.26910

Munier S, Rolland T, Diot C, Jacob Y, Naffakh N. 2013 Exploration of binary virus-host interactions using an infectious protein complementation assay. Mol Cell Proteomics 12: 2845-2855. doi:10.1074/mcp.M113.028688

Noll KE, Ferris MT, Heise MT. 2019. The collaborative cross: a systems genetics resource for studying host-pathogen interactions. Cell Host Microbe 25: 484-498. doi:10.1016/j .chom.2019.03.009

OhAinle M, Helms L, Vermeire J, Roesch F, Humes D, Basom R, Delrow JJ, Overbaugh J, Emerman M. 2018. A virus-packageable CRISPR screen identifies host factors mediating interferon inhibition of HIV. eLife 7: e39823. doi:10.7554/eLife.39823

Ong S-E, Blagoev B, Kratchmarova I, Kristensen DB, Steen H, Pandey A, Mann M. 2002. Stable isotope labeling by amino acids in cell culture, SILAC, as a simple and accurate approach to expression proteomics. Mol Cell Proteomics 1: 376-386. doi:10.1074/mcp.M200025-MCP200

Ooi YS, Majzoub K, Flynn RA, Mata MA, Diep J, Li JK, van Buuren N, Rumachik N, Johnson AG, Puschnik AS, et al 2019. An RNA-centric dissection of host complexes controlling flavivirus infection. Nat Microbiol doi: 10.1038/ s41564-019-0518-2

Paiano A, Margiotta A, De Luca M, Bucci C. 2019. Yeast twohybrid assay to identify interacting proteins. Curr Protoc Protein Sci 95: e70. doi:10.1002/cpps.70

Pickar-Oliver A, Gersbach CA. 2019. The next generation of CRISPR-Cas technologies and applications. Nat Rev Mol Cell Biol 20: 490-507. doi:10.1038/s41580-019-0131-5

Puschnik AS, Majzoub K, Ooi YS, Carette JE. 2017. A CRISPR toolbox to study virus-host interactions. Nat Rev Microbiol 15: 351-364. doi:10.1038/nrmicro.2017.29

Qi LS, Larson MH, Gilbert LA, Doudna JA, Weissman JS, Arkin AP, Lim WA. 2013. Repurposing CRISPR as an RNA-guided platform for sequence-specific control of gene expression. Cell 152: 1173-1183. doi:10.1016/j.cell .2013.02.022

Ramanathan M, Majzoub K, Rao DS, Neela PH, Zarnegar BJ, Mondal S, Roth JG, Gai H, Kovalski JR, Siprashvili Z, et al. 2018. RNA-protein interaction detection in living cells. Nat Methods 15: 207-212. doi:10.1038/nmeth.4601

Ramanathan M, Porter DF, Khavari PA. 2019. Methods to study RNA-protein interactions. Nat Methods 16: 225234. doi:10.1038/s41592-019-0330-1

Rauniyar N, Yates JR III. 2014. Isobaric labeling-based relative quantification in shotgun proteomics. J Proteome Res 13: 5293-5309. doi:10.1021/pr500880b

Rehwinkel J, Tan CP, Goubau D, Schulz O, Pichlmair A, Bier K, Robb N, Vreede F, Barclay W, Fodor E, et al. 2010. RIGI detects viral genomic RNA during negative-strand RNA virus infection. Cell 140: 397-408. doi:10.1016/j.cell.2010 .01 .020
Riley KJ, Yario TA, Steitz JA. 2012. Association of Argonaute proteins and microRNAs can occur after cell lysis. RNA 18: 1581-1585. doi:10.1261/rna.034934.112

Russell AB, Trapnell C, Bloom JD. 2018. Extreme heterogeneity of influenza virus infection in single cells. eLife 7: e32303. doi:10.7554/eLife.32303

Russell AB, Elshina E, Kowalsky JR, Te Velthuis AJW, Bloom JD. 2019. Single-cell virus sequencing of influenza infections that trigger innate immunity. J Virol 93: e00500. doi:10.1128/JVI.00500-19

Sanson KR, Hanna RE, Hegde M, Donovan KF, Strand C, Sullender ME, Vaimberg EW, Goodale A, Root DE, Piccioni F, et al. 2018. Optimized libraries for CRISPR-Cas9 genetic screens with multiple modalities. Nat Commun 9: 5416. doi:10.1038/s41467-018-07901-8

Schoggins JW, Wilson SJ, Panis M, Murphy MY, Jones CT, Bieniasz P, Rice CM. 2011. A diverse range of gene products are effectors of the type I interferon antiviral response. Nature 472: 481-485. doi:10.1038/nature09907

Schoggins JW, MacDuff DA, Imanaka N, Gainey MD, Shrestha B, Eitson JL, Mar KB, Richardson RB, Ratushny AV, Litvak V, et al. 2014. Pan-viral specificity of IFN-induced genes reveals new roles for cGAS in innate immunity. Nature 505: 691-695. doi:10.1038/nature 12862

Shalem O, Sanjana NEE, Hartenian E, Shi X, Scott DA, Mikkelsen TSS, Heckl D, Ebert BLL, Root DEE, Doench JGG, et al. 2014. Genome-scale CRISPR-Cas9 knockout screening in human cells. Science 343: 84-87. doi:10 $.1126 /$ science. 1247005

Shankavaram UT, Reinhold WC, Nishizuka S, Major S, Morita D, Chary KK, Reimers MA, Scherf U, Kahn A, Dolginow D, et al. 2007. Transcript and protein expression profiles of the NCI-60 cancer cell panel: an integromic microarray study. Mol Cancer Ther 6: 820-832. doi:10 .1158/1535-7163.MCT-06-0650

Shapira SD, Gat-Viks I, Shum BO, Dricot A, de Grace MM, Wu L, Gupta PB, Hao T, Silver SJ, Root DE, et al. 2009. A physical and regulatory map of host-influenza interactions reveals pathways in H1N1 infection. Cell 139: 1255-1267. doi:10.1016/j.cell.2009.12.018

Shoemaker RH. 2006. The NCI60 human tumour cell line anticancer drug screen. Nat Rev Cancer 6: 813-823. doi:10.1038/nrc1951

Shoemaker JE, Fukuyama S, Eisfeld AJ, Muramoto Y, Watanabe S, Watanabe T, Matsuoka Y, Kitano H, Kawaoka Y. 2012. Integrated network analysis reveals a novel role for the cell cycle in 2009 pandemic influenza virus-induced inflammation in macaque lungs. BMC Syst Biol 6: 117. doi:10.1186/1752-0509-6-117

Sigoillot FD, Lyman S, Huckins JF, Adamson B, Chung E, Quattrochi B, King RW. 2012. A bioinformatics method identifies prominent off-targeted transcripts in RNAi screens. Nat Methods 9: 363-366. doi:10.1038/nmeth .1898

Smith I, Greenside PG, Natoli T, Lahr DL, Wadden D, Tirosh I, Narayan R, Root DE, Golub TR, Subramanian A, et al 2017. Evaluation of RNAi and CRISPR technologies by large-scale gene expression profiling in the Connectivity Map. PLoS Biol 15: e2003213. doi:10.1371/journal.pbio .2003213

Soh YS, Moncla LH, Eguia R, Bedford T, Bloom JD. 2019. Comprehensive mapping of adaptation of the avian in- 
fluenza polymerase protein $\mathrm{PB} 2$ to humans. eLife 8: e45079. doi:10.7554/eLife.45079

Su G, Burant CF, Beecher CW, Athey BD, Meng F. 2011. Integrated metabolome and transcriptome analysis of the NCI60 dataset. BMC Bioinformatics 12 (Suppl. 1): S36. doi:10.1186/1471-2105-12-S1-S36

Su WC, Chen YC, Tseng CH, Hsu PW-C, Tung KF, Jeng KS, Lai MMC. 2013. Pooled RNAi screen identifies ubiquitin ligase Itch as crucial for influenza A virus release from the endosome during virus entry. Proc Natl Acad Sci 110: 17516-17521. doi:10.1073/pnas.1312374110

Sui B, Bamba D, Weng K, Ung H, Chang S, Van Dyke J, Goldblatt M, Duan R, Kinch MS, Li W-B. 2009. The use of random homozygous gene perturbation to identify novel host-oriented targets for influenza. Virology 387: 473481. doi:10.1016/j.virol.2009.02.046

Tackett AJ, DeGrasse JA, Sekedat MD, Oeffinger M, Rout MP, Chait BT. 2005. I-DIRT, a general method for distinguishing between specific and nonspecific protein interactions. J Proteome Res 4: 1752-1756. doi:10.1021/ pr050225e

Tafforeau L, Chantier T, Pradezynski F, Pellet J, Mangeot PE, Vidalain P-O, Andre P, Rabourdin-Combe C, Lotteau V. 2011. Generation and comprehensive analysis of an influenza virus polymerase cellular interaction network. J Virol 85: 13010-13018. doi:10.1128/JVI.02651-10

Terns MP. 2018. CRISPR-based technologies: impact of RNA-targeting systems. Mol Cell 72: 404-412. doi:10 .1016/j.molcel.2018.09.018

Tran AT, Rahim MN, Ranadheera C, Kroeker A, Cortens JP, Opanubi KJ, Wilkins JA, Coombs KM. 2013. Knockdown of specific host factors protects against influenza virusinduced cell death. Cell Death Dis 4: e769.

Tripathi S, Pohl MO, Zhou Y, Rodriguez-Frandsen A, Wang G, Stein DA, Moulton HM, DeJesus P, Che J, Mulder LCF et al. 2015. Meta- and orthogonal integration of influenza "OMICs" data defines a role for UBR4 in virus budding. Cell Host Microbe 18: 723-735. doi:10.1016/j.chom.2015 .11 .002

Tuladhar R, Yeu Y, Tyler Piazza J, Tan Z, Rene Clemenceau J, Wu X, Barrett Q, Herbert J, Mathews DH, Kim J, et al. 2019. CRISPR-Cas9-based mutagenesis frequently provokes on-target mRNA misregulation. Nat Commun 10: 4056. doi:10.1038/s41467-019-12028-5

Varble A, Chua MA, Perez JT, Manicassamy B, García-Sastre A, tenOever BR. 2010. Engineered RNA viral synthesis of microRNAs. Proc Natl Acad Sci 107: 11519-11524. doi:10 $.1073 /$ pnas. 1003115107

Wang T, Wei JJ, Sabatini DM, Lander ES. 2014. Genetic screens in human cells using the CRISPR-Cas9 system. Science 343: 80-84. doi:10.1126/science.1246981

Wang B, Wang M, Zhang W, Xiao T, Chen CH, Wu A, Wu F, Traugh N, Wang X, Li Z, et al. 2019. Integrative analysis of pooled CRISPR genetic screens using MAGeCKFlute. Nat Protoc 14: 756-780. doi:10.1038/s41596-018-0113-7
Approaches to Identify Host Factors for Influenza

Ward SE, Kim HS, Komurov K, Mendiratta S, Tsai PL. 2012. Host modulators of H1N1 cytopathogenicity. PLoS ONE 7: 39284. doi:10.1371/journal.pone.0039284

Watanabe T, Kawakami E, Shoemaker JE, Lopes TJ, Matsuoka Y, Tomita Y, Kozuka-Hata H, Gorai T, Kuwahara T, Takeda E, et al. 2014. Influenza virus-host interactome screen as a platform for antiviral drug development. Cell Host Microbe 16: 795-805. doi:10.1016/j.chom.2014.11 .002

WHO 2009. Influenza A (H1N1) virus resistance to oseltamivir. World Health Organization, Geneva.

Williams GD, Townsend D, Wylie KM, Kim PJ, Amarasinghe GK, Kutluay SB, Boon ACM. 2018. Nucleotide resolution mapping of influenza $A$ virus nucleoproteinRNA interactions reveals RNA features required for replication. Nat Commun 9: 465. doi:10.1038/s41467-01802886-w

* Wilson P, Lan LYL. 2019. Antibody repertoire in humans. Cold Spring Harb Perspect Med doi:10.1101/cshperspect .a038760

Winterling C, Koch M, Koeppel M, Garcia-Alcalde F, Karlas A, Meyer TF. 2014. Evidence for a crucial role of a host non-coding RNA in influenza A virus replication. RNA Biol 11: 66-75. doi:10.4161/rna.27504

* Wu NC, Wilson IA. 2019. Influenza hemagglutinin structures and antibody recognition. Cold Spring Harb Perspect Med doi:10.1101/cshperspect.a038778

Yamauchi Y, ed. 2018. Influenza virus. Humana, New York.

Yang X, Boehm JS, Yang X, Salehi-Ashtiani K, Hao T, Shen Y, Lubonja R, Thomas SR, Alkan O, Bhimdi T, et al. 2011. A public genome-scale lentiviral expression library of human ORFs. Nat Methods 8: 659-661. doi:10.1038/nmeth .1638

* Yewdell J. 2019. Original antigenic sin. Cold Spring Harb Perspect Med doi:10.1101/cshperspect.a038786

York A, Hengrung N, Vreede FT, Huiskonen JT, Fodor E. 2013. Isolation and characterization of the positive-sense replicative intermediate of a negative-strand RNA virus. Proc Natl Acad Sci 110: E4238-E4245. doi:10.1073/pnas 1315068110

York A, Hutchinson EC, Fodor E. 2014. Interactome analysis of the influenza A virus transcription/replication machinery identifies protein phosphatase 6 as a cellular factor required for efficient virus replication. J Virol 88: 13284-13299. doi:10.1128/JVI.01813-14

Zhang Y, Cao X. 2016. Long noncoding RNAs in innate immunity. Cell Mol Immunol 13: 138-147. doi:10.1038/ cmi.2015.68

Zhang L, Wang J, Muñoz-Moreno R, Kim M, Sakthivel R, Mo W, Shao D, Anantharaman A, García-Sastre A, Conrad NK, et al. 2018. Influenza virus NS1 protein-RNA interactome reveals intron targeting. J Virol 92: $\mathrm{e} 01634$ doi:10.1128/JVI.01634-18 


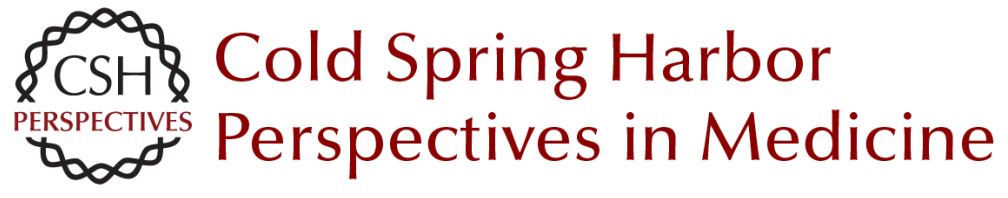

\section{Experimental Approaches to Identify Host Factors Important for Influenza Virus}

Grace A. Schaack and Andrew Mehle

Cold Spring Harb Perspect Med 2020; doi: 10.1101/cshperspect.a038521 originally published online December 23, 2019

\section{Subject Collection Influenza: The Cutting Edge}

\section{Emerging HxNy Influenza A Viruses William J. Liu, Yan Wu, Yuhai Bi, et al. \\ Equine Influenza \\ Thomas M. Chambers \\ Human Influenza Epidemiology Sukhyun Ryu and Benjamin J. Cowling}

Host Cell Factors That Interact with Influenza Virus Ribonucleoproteins Ecco Staller and Wendy S. Barclay

Induction and Evasion of Type-I Interferon Responses during Influenza A Virus Infection Raquel Muñoz-Moreno, Carles Martínez-Romero and Adolfo García-Sastre

Structure and Function of Influenza Polymerase Joanna M. Wandzik, Tomas Kouba and Stephen Cusack

H7N9 Influenza Virus in China

Chengjun Li and Hualan Chen

H5 Influenza Viruses in Egypt Rabeh El-Shesheny, Ahmed Kandeil, Ahmed Mostafa, et al.
Antivirals Targeting the Neuraminidase

Larisa Gubareva and Teena Mohan

Accessory Gene Products of Influenza A Virus Rute M. Pinto, Samantha Lycett, Eleanor Gaunt, et al.

Influenza Immunization in the Context of

Preexisting Immunity

Susanne L. Linderman, Ali H. Ellebedy, Carl Davis, et al.

Hemagglutinin Structure and Activities Steven J. Gamblin, Sébastien G. Vachieri, Xiaoli Xiong, et al.

Live Attenuated Cold-Adapted Influenza Vaccines Kanta Subbarao

Next-Generation Influenza Vaccines Masaru Kanekiyo and Barney S. Graham

\section{Selective Genome Packaging Mechanisms of Influenza A Viruses \\ Takeshi Noda}

Systems Biological Analysis of Immune Response to Influenza Vaccination

Mario Cortese, Amy C. Sherman, Nadine G.

Rouphael, et al.

For additional articles in this collection, see http://perspectivesinmedicine.cshlp.org/cgi/collection/ 